\title{
Influence of Twin-Roll Casting Speed on Microstructural Homogeneity, Centerline Segregation, and Surface Quality of Three Different Mg Alloys
}

\author{
J. VICTORIA-HERNÁNDEZ, ${ }^{1,2,3}$ G. KURZ, ${ }^{1,2}$ J. BOHLEN, ${ }^{1,2}$ \\ S. YI, ${ }^{1,2}$ and D. LETZIG ${ }^{1,2}$
}

1.-Institute of Material and Process Design, Helmholtz-Zentrum Geesthacht, Max-PlanckStrasse 1, D-21502 Geesthacht, Germany. 2.-Magnesium Innovation Centre, Helmholtz-Zentrum Geesthacht, Max-Planck-Strasse 1, D-21502 Geesthacht, Germany. 3.-e-mail: jose.victoriahernandez@hzg.de

\begin{abstract}
In this work, the influence of twin-roll casting (TRC) speed on the microstructure of the through-thickness uniformity, centerline segregation, and surface quality of three wrought $\mathrm{Mg}$ alloys was investigated. The microstructural features of the AZ31, ZX11, and ZWK200 alloys produced at TRC speeds ranging from $1.8 \mathrm{~m} / \mathrm{min}$ to $2.2 \mathrm{~m} / \mathrm{min}$ (for the AZ31 and ZWK200), and $1.5-2.5 \mathrm{~m} / \mathrm{min}$ (for the ZX11 alloy) were analyzed. There were clear differences in the microstructure uniformity depending on the alloy composition. Columnar grains coexisting with globular grains were found in the AZ31 and ZX11 alloys, whereas the ZWK200 alloy showed a homogeneous fine-grained microstructure characterized by a weaker texture even at the highest TRC speed used. While there is a tendency to reduce the centerline segregation as the TRC speed is decreased during casting of the AZ31 alloy, the formation of this defect cannot be prevented in the ZX11 and ZWK200 alloys by only varying the TRC speed.
\end{abstract}

\section{INTRODUCTION}

$\mathrm{Mg}$ and its alloys, due to their outstanding specific mechanical properties, are potential materials to be progressively introduced in structural components in many areas, especially in transport, electronics, and biomedical applications. This is based on the high strength-to-weight ratio, vibration damping, electromagnetic shielding, and biocompatibility. Furthermore, Mg exhibits good processing ability with high productivity, and is recyclable. However, in order to expand the demand of $\mathrm{Mg}$ to large tonnages, wrought products have to be implemented in transportation applications, e.g., not only automobiles but also railway and aerospace applications. Concerning the automotive industry, $\mathrm{Mg}$ die-castings dominate the manufacturing processes where the major applications include instrument panel beams, gearbox cases, steering components, engine cradles, radiator supports, etc. ${ }^{1}$

(Received November 25, 2020; accepted February 24, 2021; published online March 22, 2021)
So far, the highest weight savings in automotive structures can be achieved with the use of high performance plastics, e.g., carbon-fiber reinforced plastics (CFRP). Yet there are major obstacles that have prevented the massive use of CFRP, e.g., the high cost of raw materials, the amount of labor required to produce advanced composite parts, coating process challenges, and difficulty in recycling of composites at the vehicle's end of life. ${ }^{2}$ These problems have so far confined the use of CFRP to premium low-volume products. In this regard, wrought $\mathrm{Mg}$ alloys offer a rather similar reduction in weight potential without compromising the strength. In general, it has been pointed out that a reduction of $10 \%$ in the vehicle's weight would result in about a $6 \%$ improvement in fuel economy or a $6 \%$ increase in electric vehicle efficiency, allowing a greater range without increasing the battery size. ${ }^{1}$ In addition to this, reducing mass also improves vehicle performance attributes such as acceleration, braking, and handling. ${ }^{3}$ 
The main inherent problems that still limit the extensive use of $\mathrm{Mg}$ in structural applications are the limited formability at temperatures close to room temperature and low corrosion resistance. The poor formability arises from the lack of active deformation modes available because of preferential alignment of crystallographic orientations during thermomechanical processing, e.g., conventional hot rolling of thick $\mathrm{Mg}$ slabs. Consequently, research in $\mathrm{Mg}$ alloys has surged in recent years with the aim of improving alloy systems and processing routes to overcome these limitations, mainly by weakening the crystallographic texture. In this regard, highperformance $\mathrm{Mg}$ alloys that show formability without compromising strength have been developed by a combination of texture weakening and precipitation hardening. ${ }^{4}$ The most promising alloys for low temperature formability are the Mg-Zn-RE (ZE) and Mg-Zn-Ca (ZX) alloys. They show good formability, good corrosion resistance, and enhanced flammability resistance without sacrificing strength. $^{5-8}$ Another hurdle that limits the utilization of wrought $\mathrm{Mg}$ alloys is the high production cost. $\mathrm{Mg}$ sheets have traditionally been produced via direct chill casting (DC), in which thick slabs are hot rolled by various rolling passes. To reduce the production price of $\mathrm{Mg}$ semi-finished products, twin-roll casting (TRC) technology has been adapted from the aluminum and steel industries. ${ }^{1,9-12}$ This production process for thin strips combines solidification and rolling into one single production step and saves a number of rolling and annealing passes in comparison to the conventional rolling process. The combination of solidification-deformation allows the possibility of tailoring the microstructure for optimized formability and strength, as TRC strips already have refined microstructures, fine intermetallic particles, and increased solid solubility. ${ }^{9}$ In regard to the utilization of $\mathrm{Mg}$ sheets produced by TRC in the automobile industry, some examples include the roof of the Porsche ${ }^{\mathrm{TM}}$ GT3, the luggage retainer of the Renault-Samsung ${ }^{\mathrm{TM}}$ SM7 Nova, and the case study of the deck lid from the Cadillac ${ }^{\mathrm{TM}}$ SLS, among others. ${ }^{1,3,13}$ Although several works have reported the potential of producing $\mathrm{Mg}$ alloys via $\mathrm{TRC}$, the $\mathrm{Mg}$ alloy selection is still limited, and promising alloy compositions have only been explored at laboratory scale. Recent systematic research into TRC of a Mg-Zn-Ca-Zr (ZXK) alloy with optimized composition has shown prospective upscaling of production of this formable alloy to an industrial level. The resulting microstructure and texture after further hot rolling allowed successful forming trials of the workpiece at temperatures as low as $160{ }^{\circ} \mathrm{C} .{ }^{14}$ Although recent investigations are encouraging and have produced some insights into the influence of TRC process parameters on the resulting microstructure of TRC strips, e.g., conventional AZ31 (AZ) alloy, ${ }^{10,15}$ there is still a lack of information about key process parameters in other alloy systems. The casting speed is one of the most important TRC process parameters as it determines the location of the solidification point (sump depth) prior to deformation, and is directly related to productivity at an industrial scale. Consequently, this work provides an overview of the microstructural differences among the $\mathrm{AZ}, \mathrm{ZX}$, and $\mathrm{ZE}$ alloys mainly as a function of the TRC speed. Special emphasis is given to the microstructural throughthickness homogeneity of these alloy systems. Furthermore, possible alternative solutions for solving inherent TRC strip defects, e.g., mid-segregation and surface quality, are discussed based on promising solutions from the aluminum industry.

\section{EXPERIMENTAL PROCEDURE}

Twin-roll casting trials were carried out using a Novelis ${ }^{\text {TM }}$ Jumbo 3CM twin-roll caster facility at the Helmholtz-Zentrum Geesthacht. Strips of the AZ31 (3Al-1Zn-0.2Mn in wt.\%), the ZX11 (1Zn-1Ca in wt.\%) and the ZWK200 (2Zn-0.5Y-0.5Zr-0.5 RE mischmetal in wt.\%) alloys were cast with a width of $350 \mathrm{~mm}$. For casting, ceramic nozzles were used to cast all alloys. The targeted thickness of the TRC was set at $5.5 \mathrm{~mm}$. Some of the most important casting parameters are presented in Table I. As can be seen, representative trials (total length of cast samples) were performed for all alloys, in which the TRC speed was changed during the trial. This was done in order to investigate the effect of this important parameter on the resulting microstructure and surface quality of the produced strips. It is important to note that the selection of the temperature for each alloy was determined based on the thermodynamic calculations shown in Fig. 1. In the specific case of the AZ31 alloy, a casting trial performed at $710{ }^{\circ} \mathrm{C}$ was used for the current analysis as the variations of the speed were performed at this temperature. This is a difference of $80{ }^{\circ} \mathrm{C}$ with respect to the liquidus temperature $(630$ ${ }^{\circ} \mathrm{C}$, see Fig. 1a) of the AZ31 alloy. More results from casting temperature effects on the TRC of the AZ31 alloy can be found in. ${ }^{11,15}$ For the ZX11 alloy, an overheat of $60{ }^{\circ} \mathrm{C}$ from the liquidus temperature $\left(640{ }^{\circ} \mathrm{C}\right.$, see Fig. 1b) was used due to technical reasons, i.e., drop in the melt temperature due to melt transfer from the headbox to the ceramic nozzle. ${ }^{10}$ This casting temperature was maintained for casting the ZWK200 alloy, which also significantly reduced the difference compared with the liquidus temperature $\left(674{ }^{\circ} \mathrm{C}\right.$, see Fig. 1c) to $26{ }^{\circ} \mathrm{C}$. At this point, it has to be emphasized that the present results give only an overview of the effect of TRC speed changes for each alloy, rather than a direct comparison between them. Nevertheless, the TRC speed range used for the AZ31 and ZWK200 alloys was rather similar based on the close solidification ranges of both alloy systems. Due to the larger solidification range of the ZX11 alloy, the TRC speed was reduced further to $1.5 \mathrm{~m} / \mathrm{min}$. This was done to explore its effect on the possible 
Table I. Parameters used for twin-roll casting of $\mathrm{Mg}$ alloys

\begin{tabular}{|c|c|c|c|c|c|}
\hline Alloy & $\underset{\text { min })}{\text { TRC speed }(\mathbf{m} /}$ & $\begin{array}{c}\text { Casting temperature } \\
\left({ }^{\circ} \mathbf{C}\right)\end{array}$ & $\begin{array}{l}\text { Setback } \\
(\mathbf{m m})\end{array}$ & $\begin{array}{l}\text { Rolling force } \\
\text { (ton) }\end{array}$ & $\begin{array}{c}\text { Total length } \\
(\mathrm{m})\end{array}$ \\
\hline AZ31 & $1.8,2.0$, and 2.2 & 710 & 48 & 220 & 100.5 \\
\hline ZX11 & $1.5,2.0$, and 2.5 & 700 & 55 & 272 & 52.5 \\
\hline ZWK200 & $1.8,2.0$, and 2.2 & 700 & 49 & 255 & 73.5 \\
\hline
\end{tabular}
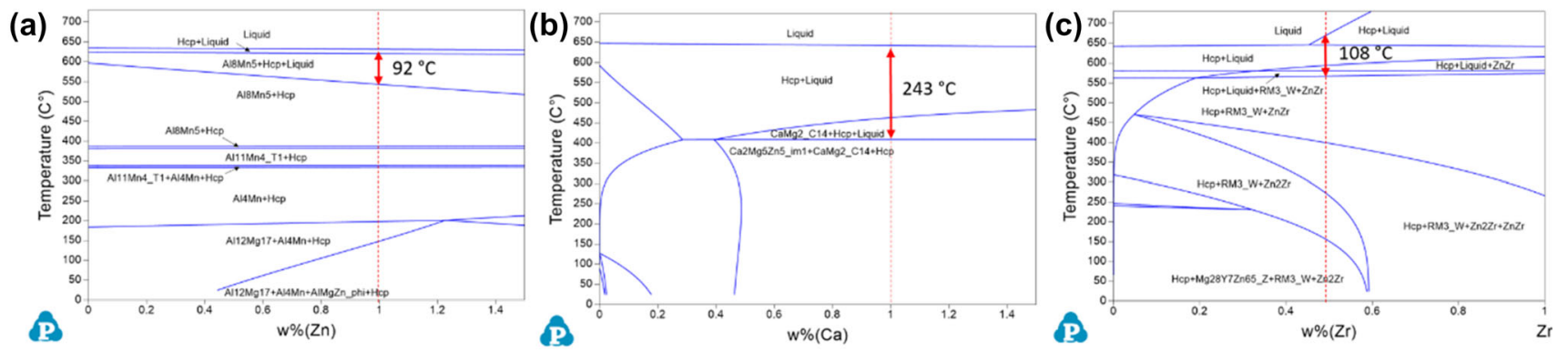

Fig. 1. Calculated phase diagrams of (a) AZ31, (b) ZX11, and (c) ZWK200 alloys using Pandat ${ }^{\mathrm{TM}}$ software.

mitigation of centerline segregation. For all TRC trials, boron nitride was used as a lubricant to prevent sticking of the melt to the rolls.

For the analysis of the resulting microstructures, samples were cut from sections of the strips produced during stable TRC conditions, i.e., $\sim 6 \mathrm{~m}$ after the respective TRC speed change. The central part of the strip was selected for further metallographic analysis. The metallographic examination was conducted by optical microscopy. Samples were ground with sandpaper from 500 grit to 2500 grit, and polished with a water-free suspension of silicon oxide (OPS $0.5 \mu \mathrm{m}$ ). Energy-dispersive x-ray spectroscopy (EDS) installed in a field emission gun scanning electron microscope (Zeiss ${ }^{\mathrm{TM}}$ Ultra 55) was performed on the mechanically polished samples to reveal the type and chemical composition of the particles mainly present on the surface and centerline segregation of the strips.

Global texture measurements were performed on the surface and the mid-plane of the TRC strips using a Panalytical ${ }^{\mathrm{TM}} \mathrm{x}$-ray diffractometer with $\mathrm{Cu}-$ $\mathrm{K} \alpha$ radiation. The orientation distribution function (ODF) was calculated using the MTEX toolbox ${ }^{16}$ from five measured pole figures (0001), $\{10 \overline{1} 0\}$, $\{10 \overline{1} 1\},\{10 \overline{1} 2\}$, and $\{11 \overline{2} 0\}$. The results are presented in terms of the recalculated (0001) and $\{10 \overline{10}$ pole figures. The surface quality of the strips in terms of the roughness was assessed in a laser scanning confocal microscope (Keyence $^{\mathrm{TM}}$ ).

\section{RESULTS AND DISCUSSION}

\section{Grain Structure}

Figure 2 shows representative microstructures of strips of the three different alloys. The AZ31 alloy (see Fig. 2a) shows different fractions of distinctive grains including deformed grains of columnar type close to the surface of the sheet, growing into the strip center. The grain structure of the strips in the mid-plane area shows globular grains as a result of the non-directional solidification. ${ }^{15}$ These globular grains are present in all strips, yet they are finer and more deformed at the lowest TRC speed. In addition to this, a strip thickness reduction is seen with increasing TRC speed. The effect of changing the TRC speed on the resulting thickness of the strips is presented in Fig. 3. With respect to the presence of impurities, they are observed at all TRC speeds (see arrows in Fig. 2a). At the lowest TRC speed, it is clear that most of the non-metallic inclusions (mainly $\mathrm{MgO}$ ) are trapped near the surface of the strip. At this point, it should be mentioned that other factors such as casting temperature, composition, and concomitant solidification range, along with changes in the TRC speed can significantly influence the formation of the observed centerline segregation. Nonetheless, for the AZ31 alloy in this study, there was a tendency for centerline segregation to develop as the TRC speed was increased. This is in good agreement with the fact that feeding molten metal to the roll gap at higher speeds will affect the velocity field and temperature distribution, i.e., the solidification front. Thus, the turbulence and non-uniform temperature gradients can lead to various casting defects such as centerline segregation ${ }^{9}$. Saxena and Sahadi ${ }^{17}$ have discussed the positive effect of reducing the TRC speed because heat transfer between the rolls and the strip is increased, thus reducing the sump depth. Furthermore, from the industrial TRC processing of $\mathrm{Al}$ alloys, it is also well 

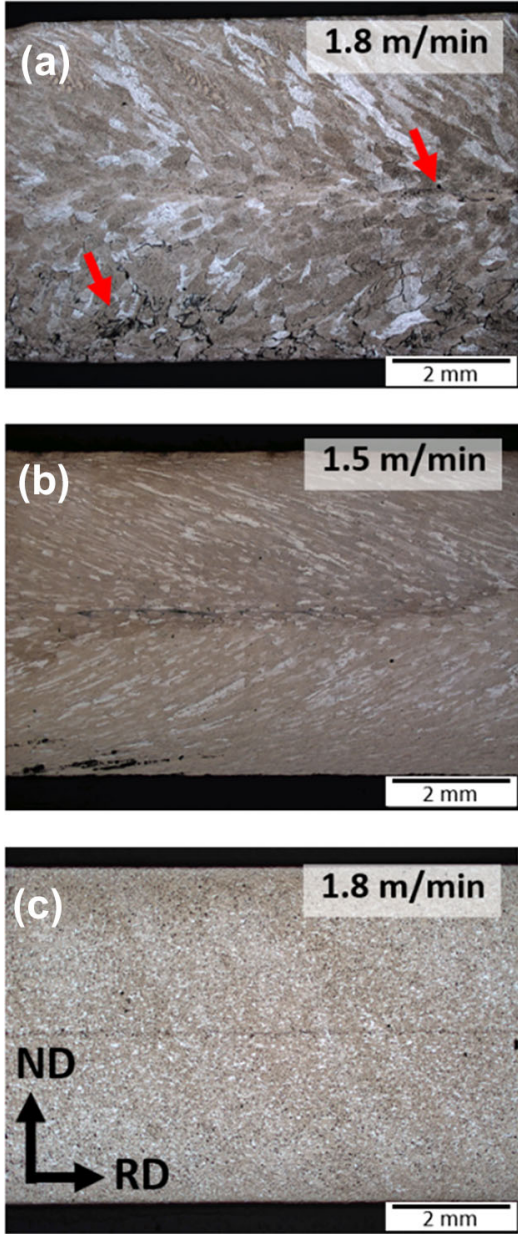
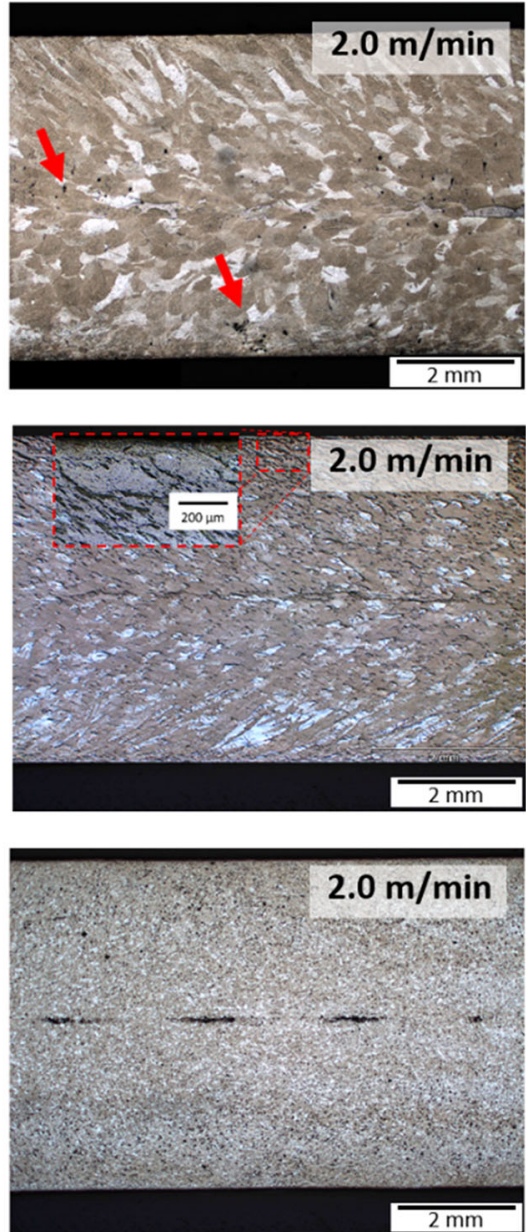
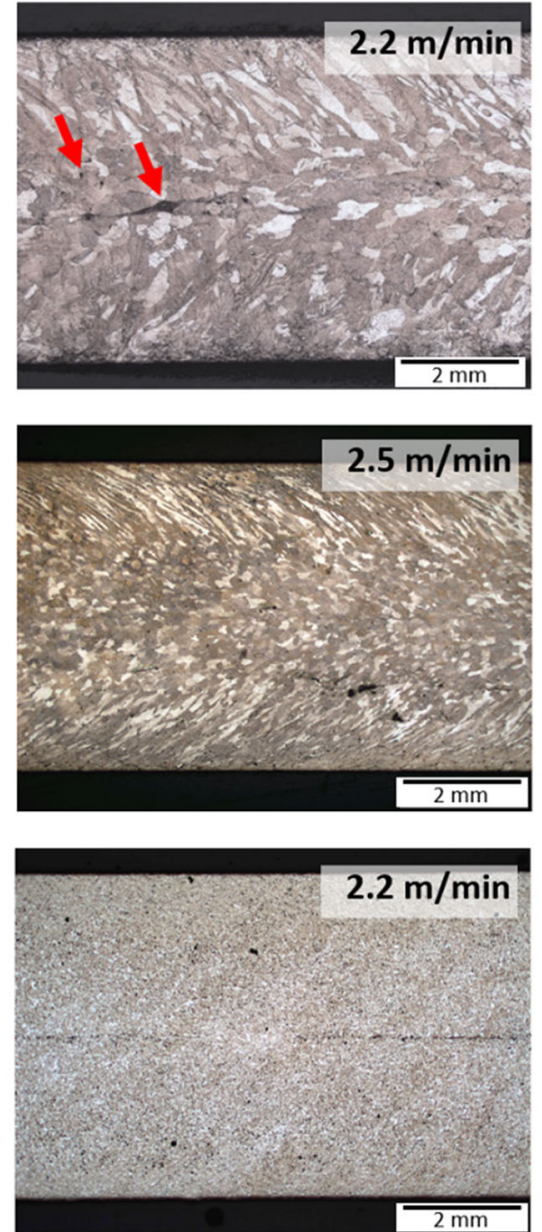

Fig. 2. Optical micrographs of TRC strips produced at different TRC speeds. (a) AZ31 cast at 1.8, 2.0, and $2.2 \mathrm{~m} / \mathrm{min}$; (b) ZX11 alloy cast at 1.5 , 2.0 , and $2.5 \mathrm{~m} / \mathrm{min}$; and (c) ZWK200 alloy cast at 1.8, 2.0, and $2.2 \mathrm{~m} / \mathrm{min}$.

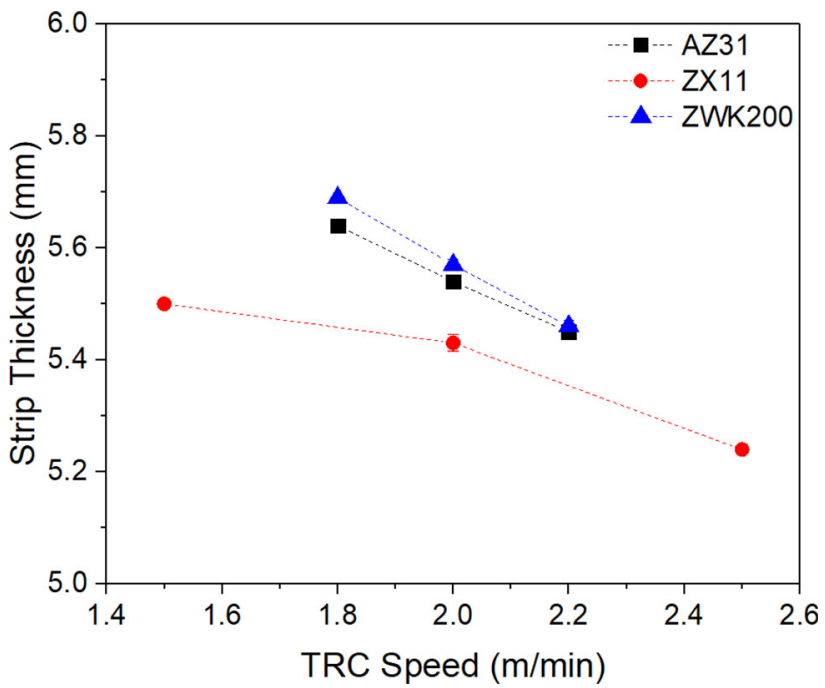

Fig. 3. Average strip thickness as a function of TRC speed for AZ31, ZX11, and ZWK200 alloys. known that an undesired large length of the sump depth can promote the development of a severe certerline segregation. Kurz et al. ${ }^{10}$ showed that a combination of low TRC speed and reduced casting temperature $\left(650{ }^{\circ} \mathrm{C}\right)$ are the optimal processing parameters for increased homogeneity in the grain structure and reduced centerline segregation in the AZ31 alloy. In order to characterize the type and composition of representative particles present near the surface and along the centerline segregation of the AZ31 alloy, EDS mapping was carried out and the results are presented in Figs. $4 \mathrm{a}$ and 5a, respectively. In this case, only the results of strips produced at $2 \mathrm{~m} / \mathrm{min}$ are presented as examples. Near the surface of the strip, there is a tendency for $\mathrm{Al}$ segregation, especially near the oxide layer. In addition to this, several small and round Al-Mn $\left(\mathrm{Al}_{8} \mathrm{Mn}_{5}\right)$ particles are distributed near this region (see Fig. 4a). In the mid-plane of the strip, several 

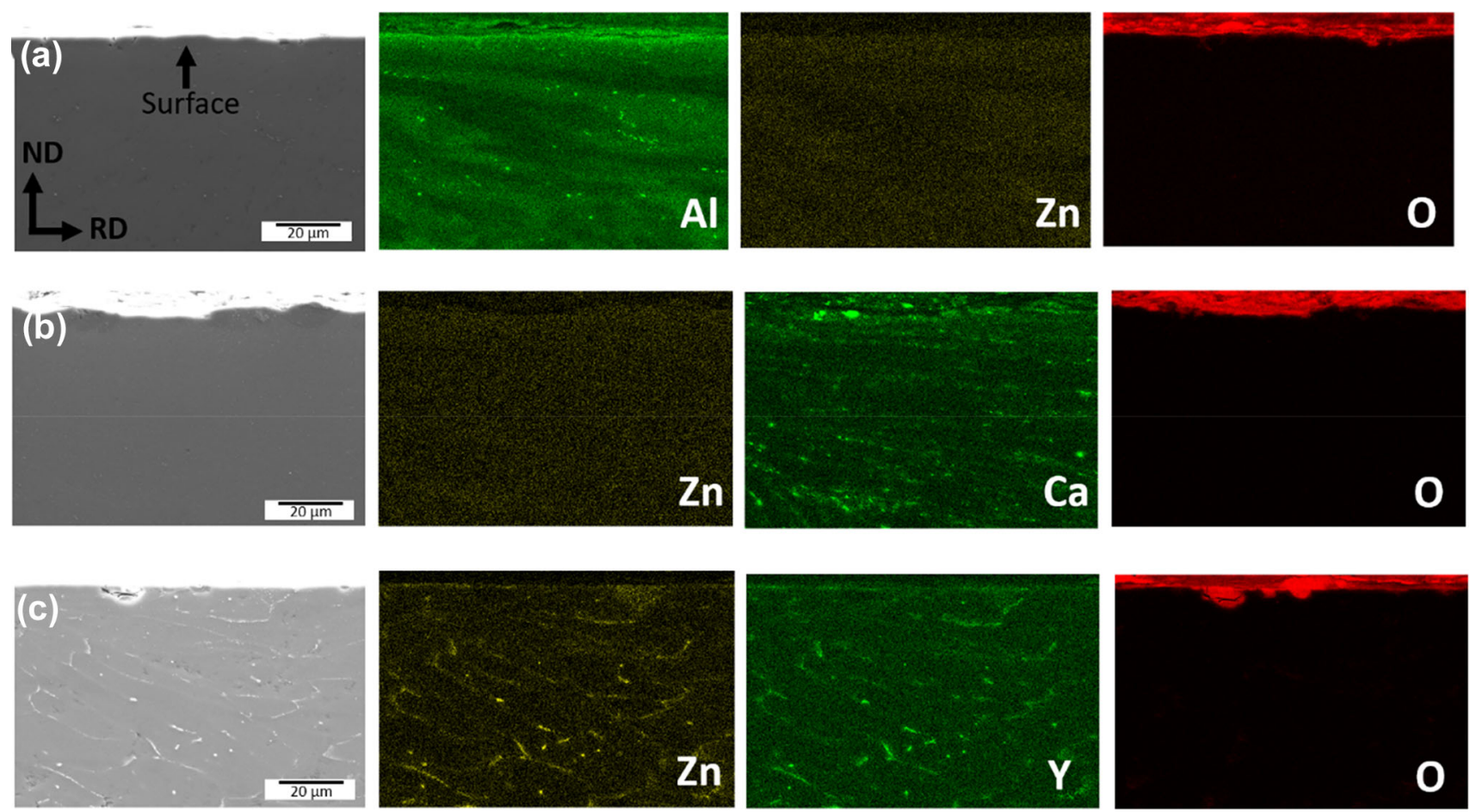

Fig. 4. EDS mapping on the surface of TRC strips cast at $2.0 \mathrm{~m} / \mathrm{min}$. (a) AZ31, (b) ZX11, and (c) ZWK200 alloys.
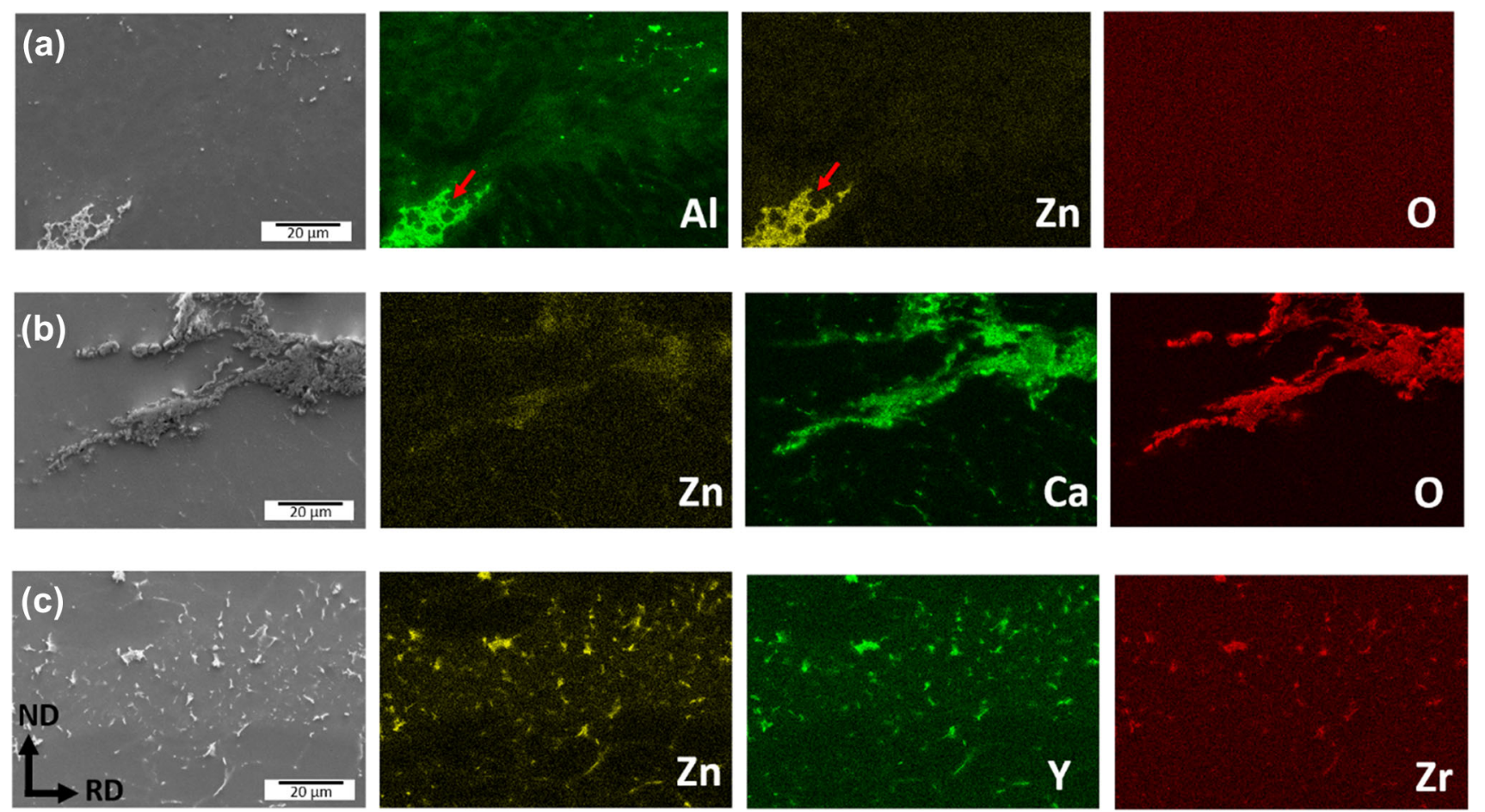

Fig. 5. EDS mapping along the centerline segregation of TRC strips cast at $2.0 \mathrm{~m} / \mathrm{min}$. (a) AZ31, (b) ZX11, and (c) ZWK200 alloys.

Al-rich particles are present; in this case not only Al-Mn particles, but also several particles of the $\mathrm{Mg}_{17} \mathrm{Al}_{12} \beta$-phase. The presence of larger $\mathrm{Zn}$-Al (46Zn-13Al wt.\%)-rich particles (see arrow in Fig. 5a) is also revealed, which may be formed as a result of non-equilibrium conditions during casting $^{18}$. These kinds of particles were consistently found along the centerline segregation.

The resulting microstructures of strips of ZX11 alloy produced at different TRC speeds are 
presented in Fig. 2b. The development of columnar grains growing from the surface towards the center of the strips is clearly visible. As a characteristic, a layer of small and highly deformed grains on the surface of the strips is observed in this alloy system (see the inset in Fig. 2b). Under all conditions, there is the existence of non-metallic inclusions. In addition, a clear formation of the centerline segregation is seen, even at the lowest TRC speed. The EDS maps revealed a tendency of Ca segregation towards the surface of the strip (see Fig. 4b). In this region, there are several small Ca-rich particles, which are mainly identified as $\mathrm{Mg}_{2} \mathrm{Ca}$ laves phase. The presence of laves phase is also observed along the midplane (see Fig. 5b). Moreover, several large $\mathrm{Ca}$ oxides were found along the centerline segregation. Although most of these particles can be fragmented at a low TRC speed and during subsequent rolling of the TRC strips, the presence of these brittle inclusions and the easy nucleation and coarsening of the $\mathrm{Mg}_{2} \mathrm{Ca}$ phase is critical in this alloy system, as they are detrimental to the formability of the final rolled sheets. ${ }^{7}$ The present results point out the need for a more holistic approach to mitigate the formation of centerline segregation and to promote the formation of a more homogeneous grain structure. In this regard, Klaumünzer et al. ${ }^{14}$ have demonstrated the beneficial effects of adding $\mathrm{Zr}$ as a grain refiner to the ZX system. Furthermore, working with a more dilute alloy content, in combination with a careful selection of TRC parameters, e.g., TRC speed, can result in strips with homogeneous, fine-grained microstructures.

The ZWK200 alloy shows a clear enhancement of microstructure homogeneity through the strip thickness (Fig. 2c). Apart from thickness reduction due to increasing the TRC speed, there is no substantial change in the microstructures, which show an equiaxed grain structure. Kim et al. ${ }^{19}$ have pointed out the good castability of the ZW (6Zn-1Y wt.\%) alloy system, which can be produced via TRC. In the present study, the addition of $\mathrm{Zr}$ leads to an improvement in the microstructure because $\mathrm{Zr}$ acts as a potent grain refiner. Despite the homogeneous and fine-grained structure, centerline segregation was observed in all examined cases. In contrast to the previous alloys, this does not show a tendency to segregate alloying elements towards the surface of the strip (see Fig. 4c). Along the mid-plane of the strip, several Zn-rich particles are found (Fig. 5c). A closer analysis of the particles present in the centerline segregations shows that they are mainly $\mathrm{Zn}$-Y-rich particles with traces of $\mathrm{Zr}$. The composition of the particles is $28 \mathrm{Zn}-12 \mathrm{Y}-7 \mathrm{Nd}-4 \mathrm{Gd}-0.5 \mathrm{Zr}$ (wt.\%). It is generally accepted that the use of grain refiners can be the solution for issues of segregation in $\mathrm{Al}$ alloys processed by $\mathrm{TRC}^{9}$. Although in the present case $\mathrm{Zr}$ was utilized as a grain refiner, it did not prevent the formation of such a defect. One of the most effective ways of reducing centerline segregation is to control the alloy solidification range. In this regard, Bae et al. ${ }^{18}$ have shown suppression of centerline segregation by using $\mathrm{Sn}$ (AT31) instead of Zn in the conventional AZ31 alloy. This change led to a significant reduction in the solidification range. Another solution can be working with more dilute alloy systems, which also maintain a low solidification range. ${ }^{14}$ However, recent studies have pointed out the potential of using more complex alloys systems, which can also be produced by TRC. One of the most promising examples is the bake hardenable Mg-Al-Zn-Mn-Ca system, ${ }^{20,21}$ which offers excellent formability with the possibility of significantly increasing its strength by artificial ageing. The persistent problem of the centerline segregation points to the need for alternative processing routes to minimize this important defect.

Melt conditioning techniques used in the TRC of aluminum alloys have shown promising results on the suppression of centerline segregation by dispersing oxides in the melt via high shearing. ${ }^{9}$ Finely dispersed particles in the melt can be transformed into potent nuclei capable of refining the microstructure. This technique has already been used in the production of TRC strips of the Mg-AZ systems, showing promising results. ${ }^{22,23}$ Men et al. ${ }^{22}$ have shown that intensive melt shearing can effectively disperse $\mathrm{MgO}$ particles, leading to a grain refinement effect. The advantage of grain refinement offered by this technique is the production of significantly thinner strips ( $1.5 \mathrm{~mm}$ thick) in comparison to the conventional thickness $(3-5 \mathrm{~mm})$ as demonstrated in. ${ }^{23}$ Despite the promising effect of grain refinement due to dispersion of $\mathrm{MgO}$, the presence of this inclusion is detrimental to the formability of the sheets, especially during the complex strain paths followed during forming operations. ${ }^{24}$ Dieringa et al. $^{25}$ have investigated the possible use of $\mathrm{CaO}$ and $\mathrm{SiC}$ as possible grain refiners, which were mixed by an intensive melt shearing. They demonstrated the possibility of increasing the hardness of the TRC strip and rolled sheets, yet with a drawback in ductility reduction. Although melt conditioning has been used for conventional $\mathrm{Mg}$ alloys, like $\mathrm{AZ}$ and AM systems, there are other promising processing techniques used in the TRC production of aluminum alloys. In this regard, TRC of aluminum alloys under the effect of electromagnetic fields has shown an important reduction in micro- and macro-segregation, leading to a reduction in centerline segregation. $^{26-28}$ These external fields can reduce the formation of centerline segregation through the electromagnetic force affecting solute migration. ${ }^{26}$ Hence, there are still other promising possibilities of enhancing the quality of more complex $\mathrm{Mg}$ alloys by using the aforementioned techniques.

\section{Crystallographic Texture}

Another important aspect of the microstructure that has a significant impact on the final mechanical 
(a)
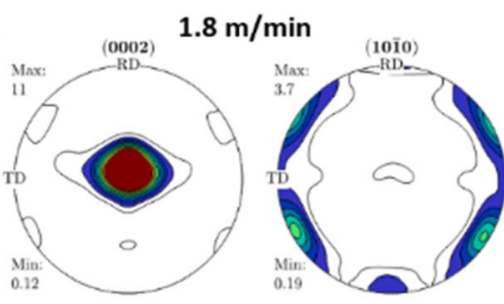

(b)
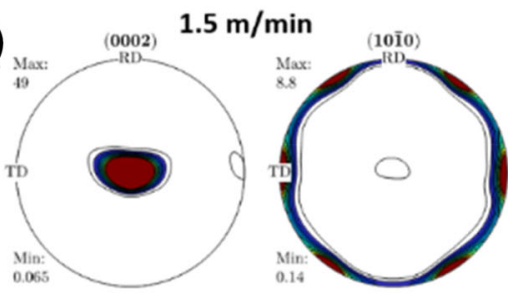

(c)
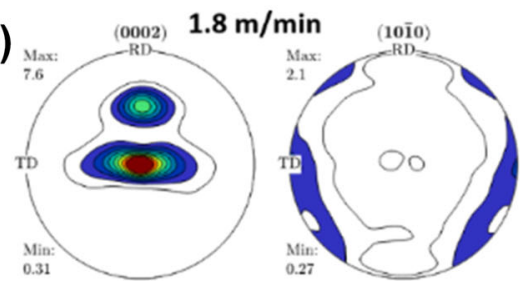
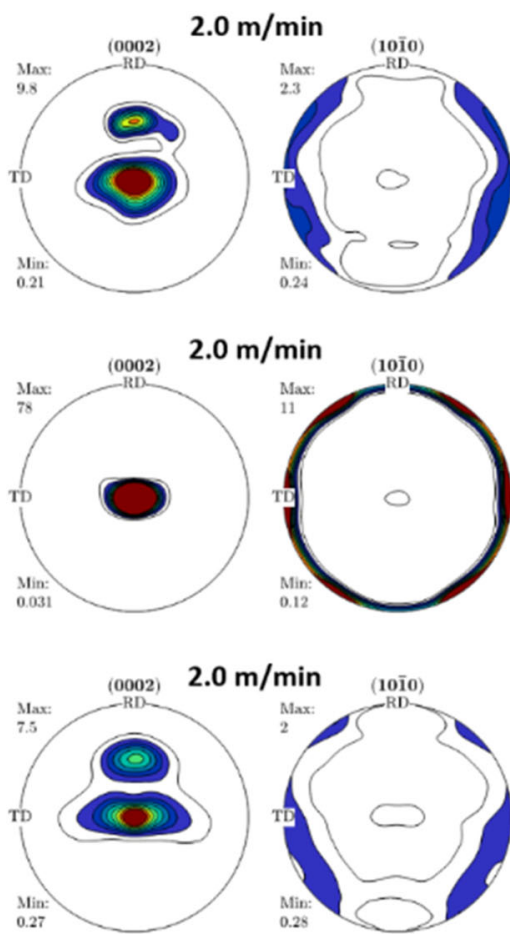
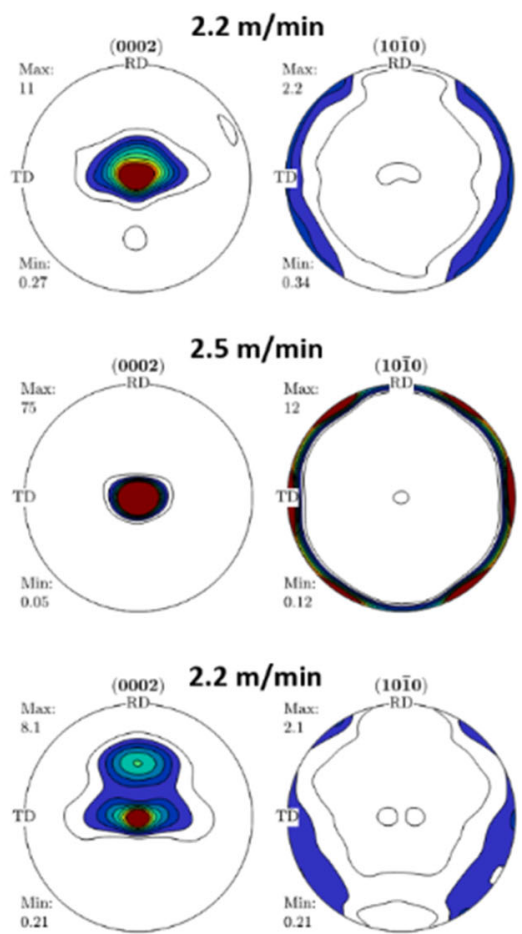

Fig. 6. Crystallographic textures on the surface of TRC strips cast at different TRC speeds. (a) AZ31, (b) ZX11, and (c) ZWK200 alloys.

(a)

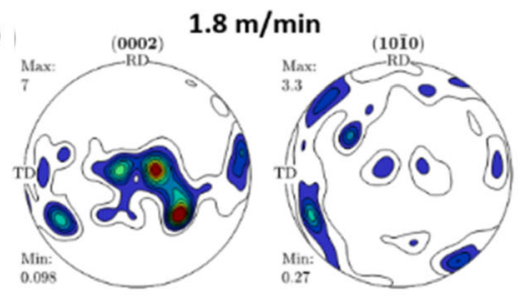

(b)
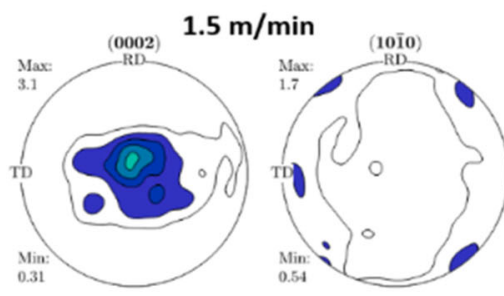

(c)
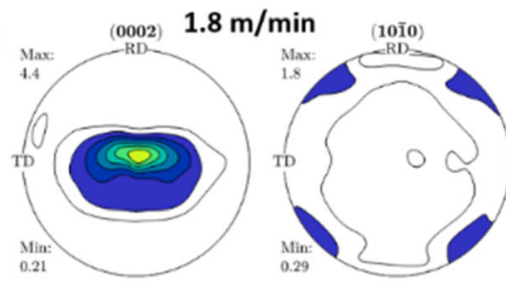
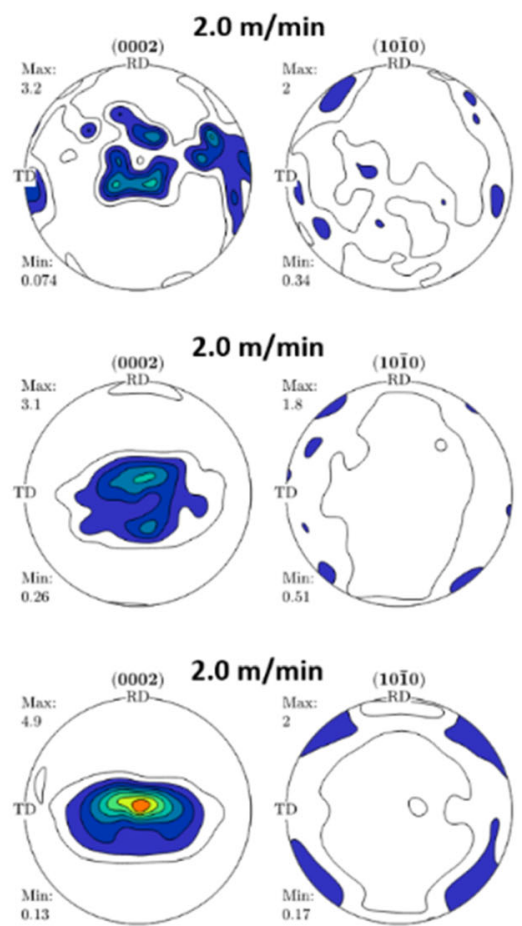
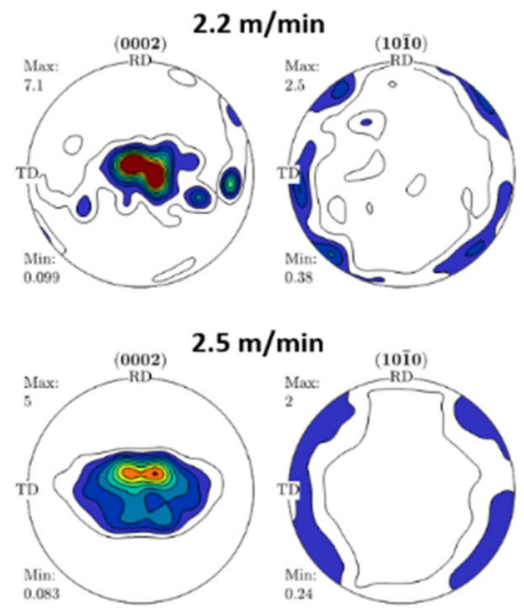

Fig. 7. Crystallographic textures on the mid-plane of TRC strips cast at different TRC speeds. (a)
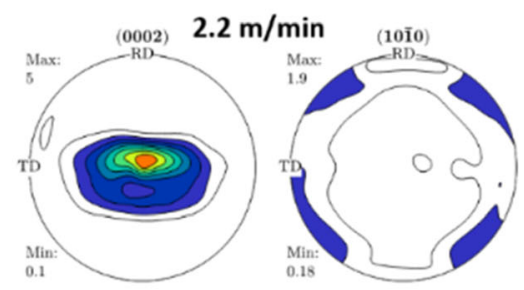

(a) AZ31,

(b) ZX11, and (c) ZWK200 alloys.

and forming properties of the processed strips is the crystallographic texture. In addition, the texture indicates the uniformity of the deformation that the strip received during TRC processing. Figure $6 \mathrm{a}$ shows the surface texture of the AZ31 alloy strip. A strong basal-type texture in which the majority of the basal planes of the hcp structure are aligned to the plane of the strip can be seen. The strips cast at 
$2.0 \mathrm{~m} / \mathrm{min}$ and $2.2 \mathrm{~m} / \mathrm{min}$ show, however, a tendency to develop a slight spread of the basal planes towards the rolling direction (RD). Figure 7a plots the corresponding textures at the mid-plane of the AZ31 alloy strips. These basal-type textures are weaker in comparison to the ones measured at the surface of the strips. This is an important finding as it would be expected that different orientations would give rise to profuse twinning activity during further hot rolling trials. Bohlen et al. ${ }^{15}$ demonstrated that an already weak basal texture in AZ31 TRC strips is important to reduce the texture intensity during subsequent rolling. Strips with basal textures show a reduction in twinning activity during subsequent rolling, allowing slightly weaker deformation textures with distinctive components, e.g., the transverse direction (TD)-texture component. The formation of strong texture components is detrimental to the forming properties of the semifinished product, as deformation along the sheet thickness would be restricted, i.e., deformation necessary during stretch forming. ${ }^{14}$ Figure $6 \mathrm{~b}$ shows the texture of the ZX11 alloy at the surface of the strip. This is the strongest texture measured in this study. It is understood that due to severe surface shear strain, the rapidly solidified nearsurface layer was strongly deformed. This fits with the presence of the strongly deformed layer of grains presented in Fig. 2b. The increase shearing on the surface of this alloy can be related to necessary adjustments of TRC parameters, i.e., setback and higher rolling force (see Table I), as a result of using a modified ceramic nozzle. In contrast to the strong texture on the surface of the strip, the mid-plane shows significantly weaker textures with a visible spread of the basal planes towards TD (see Fig. 7b). As discussed above, the present result exhibits the inhomogeneous accommodation of the deformation in alloys with large solidification ranges. Even so, further hot rolling of this alloy system can eventually homogenize the microstructure and reduce the texture gradient, leading to the formation of the distinctive TD-split texture, which has been proven to be helpful during subsequent stretch forming. ${ }^{29}$

The ZWK200 alloy also showed a strong basal texture on the surface of the strips. There is also a development of basal poles tilted towards RD (see Fig. 6c). Another characteristic is the broad spread of basal planes towards TD. This marked spread towards TD is also visible in the mid-plane of the strips (see Fig. 7c). Similarly to the ZX11 alloy, the $\mathrm{Mg}-\mathrm{Zn}$ alloy containing $\mathrm{RE}$ and $\mathrm{Y}$ tends to develop textures with a distinct spread of basal planes towards TD as a result of an enhanced activity of prismatic $<\mathrm{a}>$ slip during deformation. ${ }^{29}$

\section{Surface Quality}

It is anticipated that the surface defects of the asTRC strips can directly affect the surface quality and characteristics of the rolled sheets, e.g., probably serving as stress concentrators leading to cracking. Common TRC surface defects, e.g., deep scratches, cracks, and bleeds, can occur and are related to alloy composition. In this regard, surface bleeds are more susceptible to changes in the alloy composition and adjustments of the TRC parameters. They are pockets of solute-rich material and normally show a higher concentration of intermetallic particles. They might occur when a certain productivity/casting speed is exceeded, leading to enrichment of the molten metal to inter-dendritic regions which eventually connect with the surface of the strip. ${ }^{9}$ In an attempt to characterize the surface quality of the three different alloys in the present study, the surface topography of the strips was characterized and the results are shown in Fig. 8. It should be mentioned that the present results are also affected by the surface quality of the rolls (which had to be cleaned and reconditioned after several tests), and the handling of the strips (clamping in the pinch rolls, cutting and transport in the shear unit). Yet the present results show a consistent tendency, which can be correlated with alloy composition. Figure 8a shows the micrographs of the AZ31 alloy strips. For this alloy, scratches parallel to the rolling direction (RD), surrounded by smooth areas, are observed (see arrow in Fig. 8a). We should mention that no obvious bleeds were found in the current TRC speed range. The ZX11 alloy also shows the coexistence of smooth areas (see arrows in Fig. 8b) and traces parallel to RD. In this case, the fraction of smooth areas is considerably higher in comparison to the AZ31 alloy. The surface topography of the ZWK200 alloy shows a homogeneous surface with scratches and a reduced number of smooth areas (Fig. 8c).

For example, Fig. 9 shows the surface profile measured parallel to TD, indicated by the dashed line in Fig. 8, for samples cast at $2 \mathrm{~m} / \mathrm{min}$. The AZ31 alloy sample shows a profile that contains zones with few asperities and a small difference between the maximum peaks to valley height. In this regard, the ZX11 alloy shows a distinctive difference between the maximum peaks, which shows higher asperities in comparison to the valleys. The ZWK200 alloy, in contrast, shows a more homogeneous profile. This can be related to the lack of smooth areas as depicted in Fig. 8c. In Fig. 10 the surface roughness (Sa) for each alloy is depicted as a function the casting speed. The roughness of the AZ31 alloy shows a slight monotonic increase as the TRC speed is increased. In the case of the ZX11 alloy, there is interestingly a rather similar roughness even at the highest casting speed used in this work. This can be correlated with the rapid solidification and the formation of a protective oxide layer due to the addition of $\mathrm{Ca}$. This is in good agreement with the tendency of $\mathrm{Ca}$ to segregate near the surface, as depicted in Fig. 4b. The quick formation of a protective oxide layer is one of the 
(a)
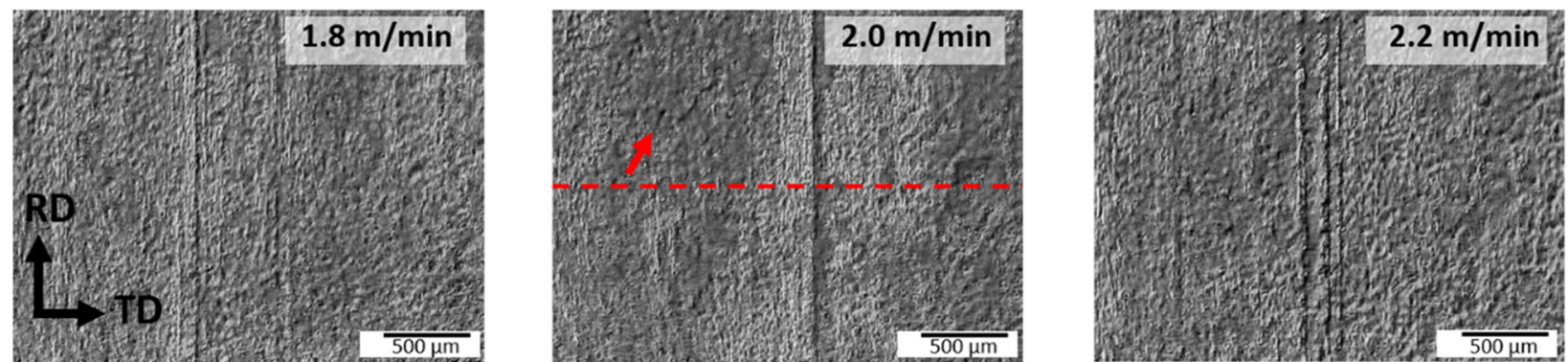

(b)
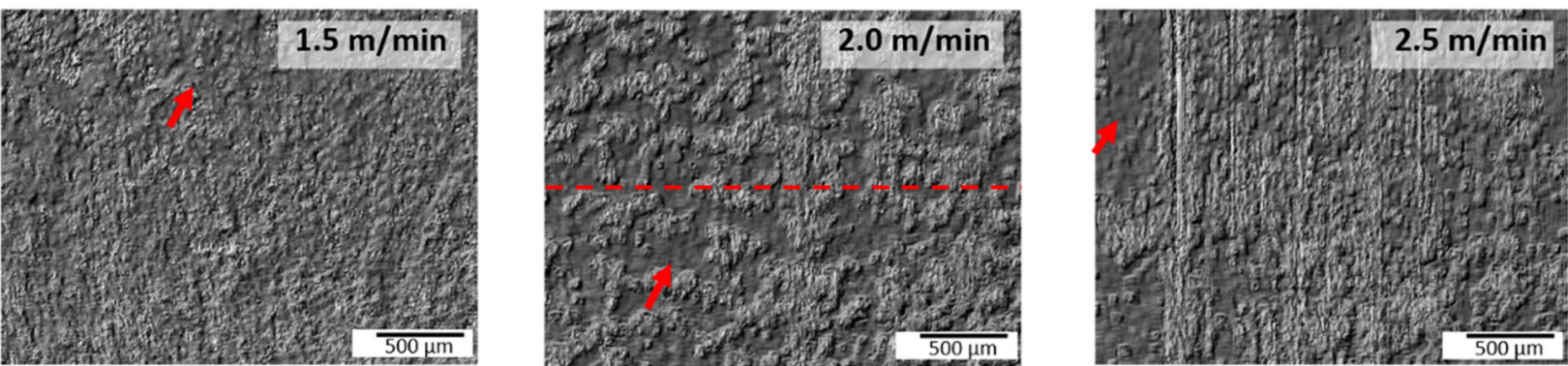

(c)
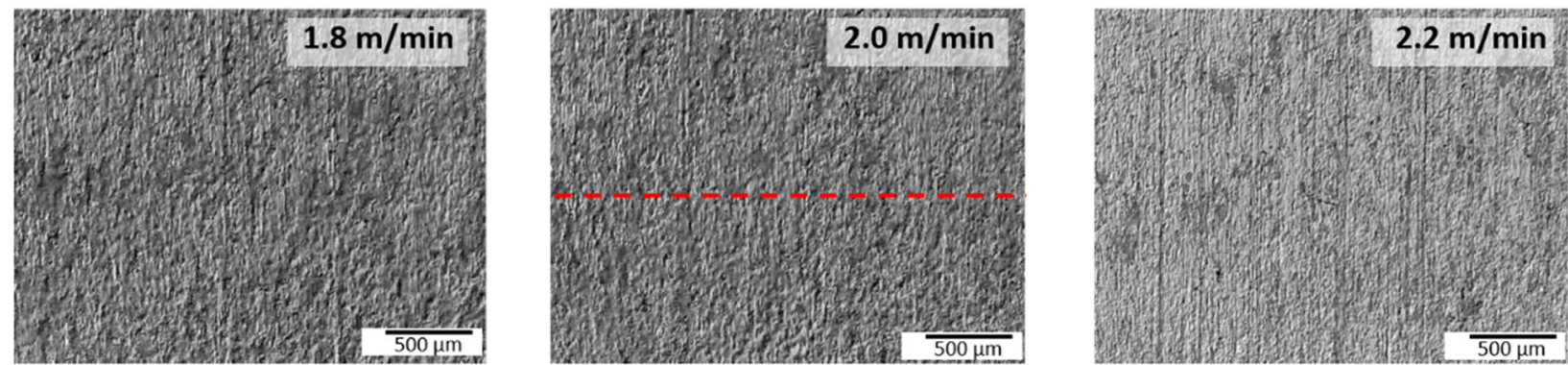

Fig. 8. Surface topography of (a) AZ31 alloy, (b) ZX11 alloy, and (c) ZWK200 alloy system produced at different TRC speeds. For the micrographs, differential interference contrast (DIC) was used.

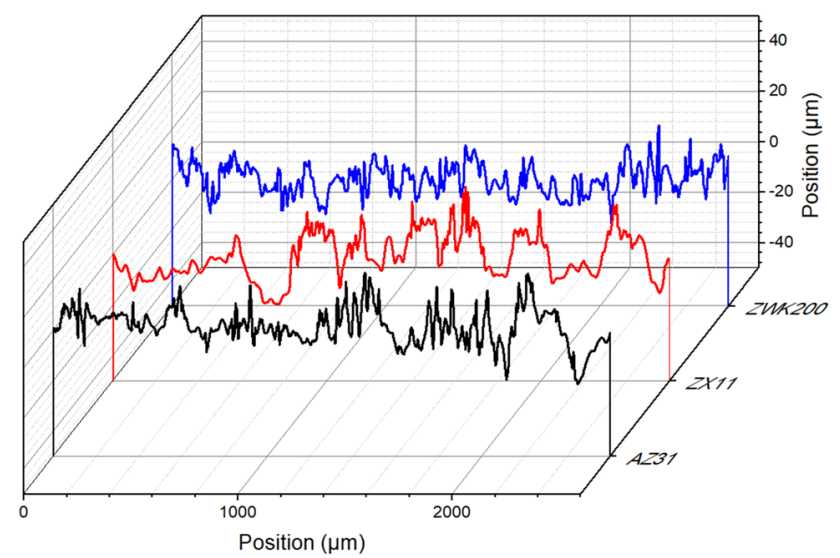

Fig. 9. Surface profiles along the dashed line in Fig. 6 for the AZ31, ZX11, and ZWK200 alloys produced at $2 \mathrm{~m} / \mathrm{min}$.

advantages of this alloy system, as the flammability resistance is also increased ${ }^{8}$. Despite the uniform surface appearance of the ZWK200 alloy at all TRC speeds (see Fig. 8c), the average roughness shows a clear increase as the TRC speed is increased. It was observed that despite the continuous lubrication, this alloy system tends to stick to the TRC rolls.

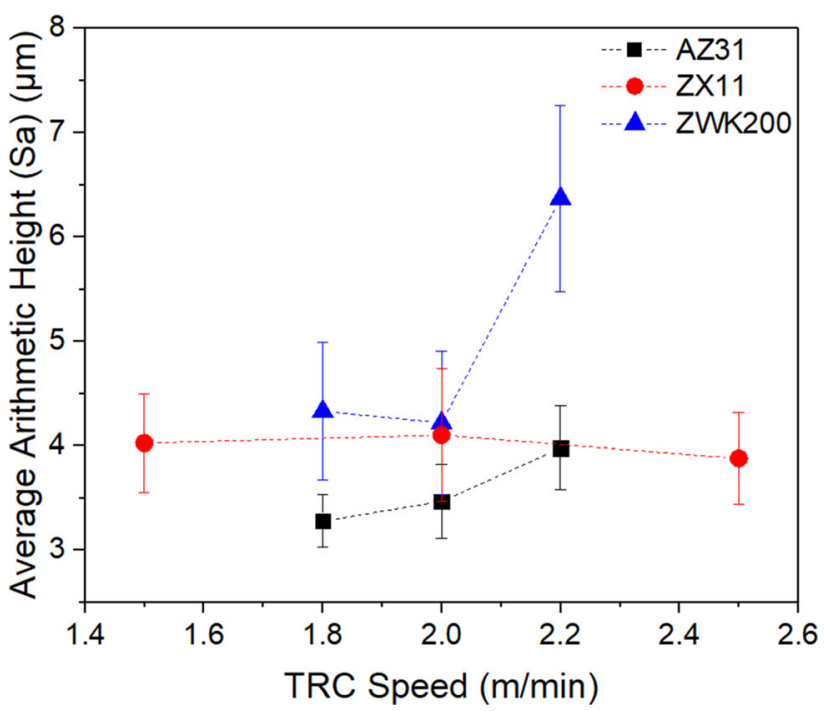

Fig. 10. Average arithmetic roughness (Sa) of $A Z 31, Z X 11$, and ZWK200 alloy systems as a function of TRC speeds.

This could be one of the reasons for the increased roughness in this alloy when produced at increased casting speeds. Therefore, the present results highlight the importance of alternative lubrication 
systems to increase the productivity of this formable alloy system.

\section{CONCLUSION}

The present work examines the microstructure characteristics of three important wrought $\mathrm{Mg}$ alloy systems able to be produced via twin-roll casting technology. As one important process parameter, the effect of different TRC speeds on the throughthickness uniformity of the microstructure, centerline segregation, and surface quality has been revealed and the following conclusions can be drawn:

- The AZ31 alloy develops distinctive microstructures with the coexistence of columnar grains and globular grains at all TRC speeds used in this work. This leads to significant differences in the crystallographic textures on the surface and the mid-plane. In addition to this, there is the tendency to develop basal-type textures in all cases, which would still allow control of the intensity of the texture in downstream processing. With regard to centerline segregation and surface quality, TRC at low speeds seems to be the best option to control these features of the strips.

- The microstructure of the ZX11 alloy also exhibits a coexistence of columnar and globular grains. There is notably a strong difference in the texture intensity between the surface and the midplane of the strips. This is due to a layer of deformed grains on the surface which are strongly influenced by the shear deformation between the quickly solidified surface and the surface of the rolls. Considering the wide solidification range of this alloy, reducing the TRC speed to $1.5 \mathrm{~m} / \mathrm{min}$ does not mitigate the migration of impurities (mainly composed of $\mathrm{CaO}$ ) to the mid-layer of the cast strip. Yet, it is hypothesized that formation of $\mathrm{CaO}$ on the melt surface may be responsible for protection of the surface of the strips, which leads to less average roughness even at the highest TRC speed used, i.e., $2.5 \mathrm{~m} / \mathrm{min}$.

- The ZWK200 alloy system developed the most homogeneous grain structure among all the alloys. This highlights the effect of $\mathrm{Zr}$ as a grain refiner. Despite the use of a grain refiner, centerline segregation was still present, even at the lowest TRC speed used. This could be improved by carefully adjusting the alloy composition, e.g., using a more dilute alloy composition. In agreement with the grain structure uniformity, there was a small difference between the texture intensities on the surface and the mid-plane of the strips under all conditions examined.

\section{FUNDING}

Open Access funding enabled and organized by Projekt DEAL.

\section{CONFLICT OF INTEREST}

On behalf of all authors, the corresponding author states that there is no conflict of interest.

\section{OPEN ACCESS}

This article is licensed under a Creative Commons Attribution 4.0 International License, which permits use, sharing, adaptation, distribution and reproduction in any medium or format, as long as you give appropriate credit to the original author(s) and the source, provide a link to the Creative Commons licence, and indicate if changes were made. The images or other third party material in this article are included in the article's Creative Commons licence, unless indicated otherwise in a credit line to the material. If material is not included in the article's Creative Commons licence and your intended use is not permitted by statutory regulation or exceeds the permitted use, you will need to obtain permission directly from the copyright holder. To view a copy of this licence, visit $h$ ttp://creativecommons.org/licenses/by/4.0/.

\section{REFERENCES}

1. C. Romanowski, Magnesium Technology, ed. V. Joshi, L. Jordon, D. Orlov and N. Neelameggham (TMS: Springer, 2019), p. 3.

2. A. Bandivadekar, K. Bodek, L. Cheah, C. Evans, T. Groode, J. Heywood, E. Kasseris, M. Kromer, and M. Weiss, MIT LFEE, Report No. LFEE 2008-05 RP (2008).

3. W.J. Joost, and P.E. Krajenwski, W.J. Joost, and P.E. Krajenwski, Scr. Mater. 128, 107. (2017).

4. T.T.T. Trang, J.H. Zhang, J.H. Kim, A. Zargaran, J.H. Hwang, B.-C. Suh, and N.J. Kim, Nat. Commun. 9, 2522. (2018).

5. N.J. Kim, N.J. Kim, Mater. Sci. Technol. 30(15), 1925. (2014).

6. R. Hou, J. Victoria-Hernandez, P. Jiang, R. Willumeit-Römer, B. Luthringer-Feyerabend, S. Yi, D. Letzig, and F. Feyerabend, Acta Biomater. 97, 608. (2019).

7. J. Victoria-Hernandez, S. Yi, D. Klaumünzer, and D. Letzig, Front. Mater. 6, 288. (2019).

8. S. Yi, J. Victoria-Hernandez, Y.M. Kim, D. Letzig, and B.S. You, Metals 9(2), 181. (2019).

9. N.S. Barekar, and B.K. Dhindaw, Mater. Manuf. Process. 29, 651. (2014).

10. G. Kurz, J. Bohlen, D. Letzig, and K.U. Kainer, Mater. Sci. Forum 765, 205. (2013).

11. G. Kurz, J. Bohlen, L. Stutz, D. Letzig, and K.U. Kainer, Magnesium Technology, ed. N. Hort, S.N. Mathaudhu, N.R. Neelameggham, M. Alderman (TMS: Springer, 2013) p.365.

12. M. Ullman, K. Kittner, T. Henseler, A. Stöcker, U. Prahl, and R. Kawalla, Procedia Manuf. 27, 203. (2019).

13. G. Kurz, J. Wendt, J. Bohlen, and D. Letzig, Magnesium Technology, ed. M.V. Manuel, A. Singh, M. Alderman and N.R. Neelameggham (TMS: Wiley, 2015), p. 465.

14. D. Klaumünzer, J. Victoria-Hernandez, S. Yi, D. Letzig, S.H. Kim, J.J. Kim, M.H. Seo, and K. Ahn, Magnesium Technology, ed. V. Joshi, J. Jordon, D. Orlov and N. Neelameggham (TMS: Springer, 2019), p. 15.

15. J. Bohlen, S. Yi, J. Victoria-Hernández, N. Schell, B. Schwebke, H.G. Brokmeier, G. Kurz, and D. Letzig, Magnesium Technology, ed. M.V. Manuel, A. Singh, M. Alderman and N.R. Neelameggham (TMS: Wiley, 2015), p. 471.

16. R. Hielscher, and H. Schaeben, J. Appl. Crystallogr. 41, 1024. (2008). 
17. A. Saxena, and Y. Sahai, Metall. Mater. Trans. A 43-2, 214. (2002).

18. J.H. Bae, M.S. Shim, B.-C. Suh, D.W. Kim, S.H. Park, and N.J. Kim, Mater. Lett. 132, 361. (2014).

19. K.H. Kim, B.-C. Suh, J.H. Bae, M.S. Shim, S. Kim, and N.J. Kim, Scr. Mater. 63, 716. (2010).

20. M.Z. Bian, T.T. Sasaki, T. Nakata, Y. Yoshida, N. Kawabe, S. Kamado, and K. Hono, Acta Mater. 158, 278. (2018).

21. Z.H. Li, T.T. Sasaki, M.Z. Bian, T. Nakata, Y. Yoshida, N. Kawabe, S. Kamado, and K. Hono, J. Alloys Compd. 847, 156347. (2020).

22. H. Men, B. Jiang, and Z. Fan, Acta Mater. 58, 6526. (2010).

23. X. Yang, J.B. Patel, Y. Huang, C.L. Mendis, and Z. Fan, Mater. Des. 179, 107887. (2019).

24. J. Suh, J. Victoria-Hernandez, D. Letzig, R. Golle, and W. Volk, Mater. Sci. Eng. A 669, 159. (2016).
25. H. Dieringa, S. Das, D. Eskin, Z. Fan, L. Katsarou, M. Horstmann, G. Kurz, C.L. Mendis, N. Hort, and K.U. Kainer, Mater. Sci. Forum 828-829, 35. (2015).

26. K.M. Sun, L. Li, S.D. Chen, G.M. Xu, G. Chen, R.D.K. Misra, and G. Zhang, Mater. Lett. 190, 205. (2017).

27. S. Li, T. Jiang, J. Wang, L. Chen, B. Wie, Y. Li, G. Xu, and Z. Wang, Mater. Sci. Eng. A 757, 14. (2019).

28. S. Li, B. Wei, C. Yu, Y. Li, G. Xu, and Y. Li, J. Mater. Res. Technol. 9(3), 3304. (2020).

29. J. Victoria-Hernandez, S. Yi, D. Klaumünzer, and D. Letzig, Mater. Sci. Eng. A 761, 138054. (2019).

Publisher's Note Springer Nature remains neutral with regard to jurisdictional claims in published maps and institutional affiliations. 